\title{
Anti-Inflammatory, Analgesic Evaluation and Molecular Docking Studies of N-Phenyl Anthranilic Acid-Based 1,3,4-Oxadiazole Analogues
}

\author{
Suman Bala, ${ }^{1}$ Sunil Kamboj, ${ }^{1}$ Vipin Saini, ${ }^{1}$ and D. N. Prasad ${ }^{2}$ \\ ${ }^{1}$ M. M. College of Pharmacy, Maharishi Markandeshwar University, Mullana, Ambala, Haryana 133207, India \\ ${ }^{2}$ Shivalik College of Pharmacy, Nangal, Ropar, Punjab 140126, India \\ Correspondence should be addressed to Suman Bala; sumankmj7@gmail.com
}

Received 31 May 2013; Accepted 21 August 2013

Academic Editor: Frank Wuest

Copyright (C) 2013 Suman Bala et al. This is an open access article distributed under the Creative Commons Attribution License, which permits unrestricted use, distribution, and reproduction in any medium, provided the original work is properly cited.

A novel series of $\mathrm{N}$-phenyl anthranilic acid-based 1,3,4-oxadiazoles were prepared (4a-h) and subjected to anti-inflammatory, analgesic activity and molecular docking studies to target cyclooxygenase-2 enzyme. 1,3,4-Oxadiazole derivatives were screened for anti-inflammatory activity in carrageenan-induced rat paw edema and analgesic activity by tail immersion method. In synthesized compounds, the free carboxylic group, which is responsible for gastric side effects, was derivatized by heterocyclic 1,3,4-oxadiazole bioactive core, which showed good interaction with COX-2 receptor with good docking score. Among all the synthesized compounds, $\mathbf{4 e}$ and $\mathbf{4} \mathbf{f}$ have emerged out as potential COX-2 inhibitors.

\section{Introduction}

Non-steroidal anti-inflammatory drugs (NSAIDs) form an important class of widely used therapeutic agents due to their anti-inflammatory, analgesic and antipyretic effects. The pharmacological activity of NSAIDs is related to suppression of prostaglandin biosynthesis by inhibiting the enzyme cyclooxygenase (COX). COX is an endogenous enzyme which catalyzes the conversion of arachidonic acid into prostaglandins and thromboxanes. The enzyme exists in at least two isoforms, COX-1 and COX-2. Although both isoforms catalyze the same biochemical transformation, they are subject to a different expression regulation. COX-1 is a constitutive enzyme and is responsible for the physiological function of prostaglandins (PGs) like maintenance of the integrity of the gastric mucosa and provides adequate vascular homeostasis whereas COX-2 is an inducible enzyme and is expressed only after an inflammatory stimulus [1].

With the chronic use of NSAIDs, one prominent side effect is the formation of gastric ulcers. Heterocyclic compounds containing five-membered oxadiazole nucleus possess a diversity of useful biological effects such as antiedema and anti-inflammatory activities. 1,3,4-Oxadiazoles have anti-inflammatory activity by virtue of dual mechanism, that is, inhibiting both COX/LOs to reduce gastric ulcer formation [2]. Literature studies suggest that direct tissue contact of NSAIDs plays an important role in the production of side effects like gastric upset, irritation, and ulceration $[3,4]$, and the reported literature confirms that gastrointestinal side effects of NSAIDs such as irritation and GI bleeding are due to the presence of a free carboxylic group in the parent drug $[5,6]$. Thus, developing new agents with minimum or without side effects is an extensive research area in the present scenario. Our studies and studies of other researchers [6] have shown that derivatization of the carboxylate function of some NSAIDs resulted in an increased anti-inflammatory activity with a reduced ulcerogenic effect. Hence, it is not irrelevant to speculate that replacing the terminal carboxylic function of NSAIDs by oxadiazole ring, a five membered heterocyclic nucleus, may enhance the anti-inflammatory activity of such compounds. Hence, by incorporating the oxadiazolyl moiety, we hope to get a better anti-inflammatory molecule. 


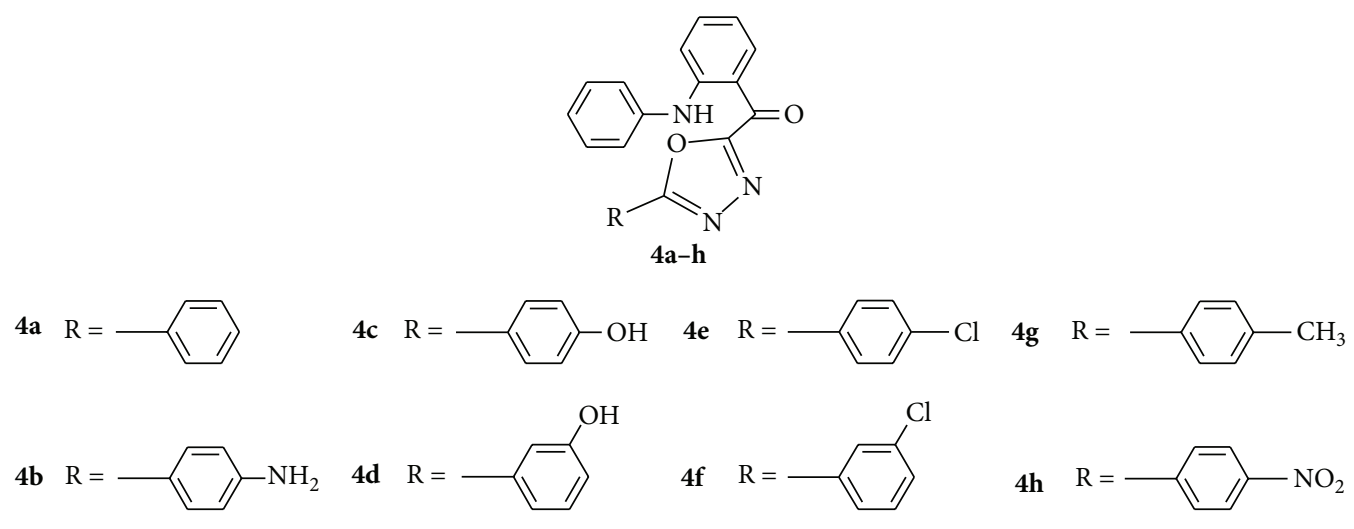

FIGURE 1: N-Phenyl anthranilic acid-based substituted 1,3,4-oxadiazole analogues (4a-h).

\section{Material and Method}

2.1. Preparation of Target Compounds. Target compounds $(\mathbf{4 a}-\mathbf{h})$ were prepared previously in our laboratory [7] (Figure 1). The aromatic esters were prepared by Fischer esterification. Further, these esters were subjected to formation of aryl hydrazide in presence of hydrazine hydrate. Aryl hydrazide $2 \mathrm{a}(1 \mathrm{M})$ was dissolved in phosphorous oxychloride $(5 \mathrm{~mL})$, and to it compound 3 (equimolar; $1 \mathrm{M}$ ) was added. The reaction mixture, after refluxing for 6-7 h, was cooled to room temperature and poured onto crushed ice. On neutralization of the contents with sodium bicarbonate solution (20\%), a solid mass separated out. It was filtered and washed with water. It was crystallized by using methanol to give 4a. Similarly, compounds $\mathbf{4 b}-\mathbf{h}$ were prepared. The physical properties and spectral characterization were already discussed [7].

2.2. Chemicals and Instruments. All chemicals used in the estimation were of analytical grade. Carrageenan was purchased from Sigma Chemicals. A digital plethysmometer (model pth-7070, sr.no.pt 070509, Medicad system) was used for measuring paw volume $(\mathrm{mL})$ of rats edema. Molecular docking studies were carried out on Molecular Virtual Docker 5.0.0.

2.3. Animals. Albino rats of either sex, around 180-200 g of weight, were selected for both anti-inflammatory and analgesic activity, respectively. The animals were kept in polypropylene cages ( 3 in each cage) at an ambient temperature of $20 \pm 2^{\circ} \mathrm{C}$ and $55-65 \%$ relative humidity. A 12 $12 \mathrm{hrs}$ light and dark schedule was maintained in the animal house. The rats had free access to water and food. The experimental protocol was approved by the Institutional Animals Ethical Committee (MMCP/IEC/10/16), and animal care was done as per the guidelines of the committee for the purpose of control and supervision of experiments on animals (CPCSEA), Government of India.

2.4. Acute Toxicity Studies. It has been fund from the literature survey that 1,3,4-oxadiazole derivatives in a dose of $1000 \mathrm{mg} / \mathrm{kg}$ produce mortality $\left(\mathrm{LD}_{50}\right)$ in rats. Soon, tenth of the $\mathrm{LD}_{50}$, that is, $100 \mathrm{mg} / \mathrm{kg}\left(\mathrm{ED}_{50}\right)$, was selected as a dose for anti-inflammatory and analgesic activity [8].

2.5. In Vivo Anti-Inflammatory Activity. In carrageenan model, albino rats of all groups were treated with subcutaneous injection of $0.1 \mathrm{~mL}$ of $1 \% \mathrm{w} / \mathrm{v}$ solution of carrageenan into the subplantar region of the right hind paw. The paw was marked with permanent marker at the planter region where the paw volume was to be measured. The diclofenac sodium $(10 \mathrm{mg} / \mathrm{kg})$ and test compounds $(100 \mathrm{mg} / \mathrm{kg})$ were suspended in $0.3 \%$ sodium carboxy methyl cellulose. The test compounds and vehicle (control) were administered p.o. with the help of gastric cannula half an hour after the injection of carrageenan in subplanter region of right paw. Mean normal paw volume was measured $30 \mathrm{~min}$ prior to carrageenan injection by using plethysmometer. Mean increase in the paw volume for control group (after carrageenan injection) and test group was measured at $1 \mathrm{hr}, 2 \mathrm{hr}$, and $3 \mathrm{hr}$ [9]. Percent inhibition of inflammation after test/standard was calculated using the formula

$$
\% \text { inhibition }=\frac{V_{c}-V_{t}}{V_{c}} \times 100,
$$

where $V_{t}$ is the of paw volume $(\mathrm{mL})$ of test/standard compound at corresponding time and $V_{c}$ is the paw volume $(\mathrm{mL})$ of control.

2.6. Analgesic Activity. Tail immersion method is based on the observation that morphine-like drugs selectively prolong the reaction time of the typical tail withdrawal reflex in mice. Albino rats were divided in twenty-six groups each containing six animals. The tail of mice was immersed (1$2 \mathrm{~cm}$ ) in warm water kept constant at $55^{\circ} \mathrm{C}$. The reaction time was recorded by stopwatch (the reaction time is the time taken by the rats to flick their tails). The latent period of the tail flick response will be determined before and 15, 30, 60, and 120 min after drug administration [10].

2.7. Statistical Analysis. The results were expressed as mean \pm SEM for six animals in each group for anti-inflammatory and analgesic activity. All the grouped data was statistically evaluated. Hypothesis testing method included one-way analysis of 
TABLE 1: In vivo anti-inflammatory activity of synthesized 1,3,4-oxadiazole analogues.

\begin{tabular}{lcccccc}
\hline \multicolumn{7}{c}{ Change in paw edema volume $(\mathrm{mL})$} \\
Groups & $1 \mathrm{~h}$ & Percentage inhibition & $2 \mathrm{~h}$ & Percentage inhibition & $3 \mathrm{~h}$ & Percentage inhibition \\
\hline Control & $0.43 \pm 0.05$ & - & $0.72 \pm 0.06$ & - & $0.98 \pm 0.09$ & - \\
Diclofenac sodium $(10 \mathrm{mg} / \mathrm{kg})$ & $0.25 \pm 0.03$ & 57.13 & $0.30 \pm 0.02$ & 58.33 & $0.26 \pm 0.01$ & 73.46 \\
$\mathbf{4 a}(100 \mathrm{mg} / \mathrm{kg})$ & $0.40 \pm 0.05$ & 6.97 & $0.61 \pm 0.08$ & 15.28 & $0.69 \pm 0.06$ & 29.59 \\
$\mathbf{4 b}(100 \mathrm{mg} / \mathrm{kg})$ & $0.39 \pm 0.01$ & 9.30 & $0.60 \pm 0.06$ & 16.66 & $0.59 \pm 0.04$ & 39.79 \\
$\mathbf{4 c}(100 \mathrm{mg} / \mathrm{kg})$ & $0.38 \pm 0.05$ & 11.6 & $0.48 \pm 0.04$ & 33.34 & $0.45 \pm 0.03$ & 54.08 \\
$\mathbf{4 d}(100 \mathrm{mg} / \mathrm{kg})$ & $0.36 \pm 0.01$ & 16.27 & $0.52 \pm 0.03$ & 27.78 & $0.49 \pm 0.04$ & 50 \\
$\mathbf{4 e}(100 \mathrm{mg} / \mathrm{kg})$ & $0.29 \pm 0.02^{*}$ & 32.55 & $0.38 \pm 0.04^{*}$ & 47.23 & $0.31 \pm 0.02^{*}$ & 68.36 \\
$\mathbf{4 f}(100 \mathrm{mg} / \mathrm{kg})$ & $0.34 \pm 0.05$ & 20.9 & $0.43 \pm 0.03^{*}$ & 40.28 & $0.36 \pm 0.06^{*}$ & 63.26 \\
$\mathbf{4 g}(100 \mathrm{mg} / \mathrm{kg})$ & $0.36 \pm 0.05$ & 16.27 & $0.55 \pm 0.02$ & 23.61 & $0.55 \pm 0.05$ & 43.87 \\
$\mathbf{4 h}(100 \mathrm{mg} / \mathrm{kg})$ & $0.35 \pm 0.01$ & 18.6 & $0.46 \pm 0.02$ & 36.12 & $0.44 \pm 0.03$ & 53.10 \\
\hline
\end{tabular}

All values are expressed as means $\pm \operatorname{SEM}(n=6),{ }^{*} P<0.05$ versus control.

variance (ANOVA) followed by Dunnett's comparison test. $P$ values of less than 0.05 were considered to indicate statistical significance.

2.8. Molecular Docking Studies. Comparative docking of a set of ligands with specific proteins involves methodology with easy user interface and their respective scoring function provided by Molegro Virtual Docker. Molecular docking studies were performed to target COX-2. The compounds which have shown potent anti-inflammatory and analgesic activity (4e and $\mathbf{4 f}$ ) were subjected to molecular docking to target COX-2 (Pdb-1CX2) [11, 12].

Steps in methodology are as follows:

(1) importing a protein file and ligand file and preparation of ligands;

(2) protein preparation and detecting cavities of protein molecules;

(3) executing a docking setup through docking wizard panel;

(4) poses of protein-ligand complexes obtained after docking process with their specific mol dock scores displayed in output file.

\section{Results}

3.1. In Vivo Anti-Inflammatory Activity. 1,3,4-Oxadiazole compounds were evaluated for anti-inflammatory activity in carrageenan-induced rat paw edema. Among all the compounds, $\mathbf{4 e}$ and $\mathbf{4 f}$ have shown maximum activity at $100 \mathrm{mg} / \mathrm{kg}$ (Table 1) (Figure 2).

3.2. Analgesic Activity. 1,3,4-Oxadiazole compounds were evaluated for analgesic activity by tail immersion method. Among all the compounds, $\mathbf{4 e}$ and $\mathbf{4 f}$ have shown maximum analgesic activity at $100 \mathrm{mg} / \mathrm{kg}$ (Table 2) (Figure 3).

3.3. Molecular Docking Studies. 1,3,4-Oxadiazole compounds were subjected to molecular docking to target COX-2. Compounds $\mathbf{4 e}$ and $\mathbf{4 f}$ have shown good interaction with COX2. The interaction of ligands $\mathbf{4} \mathbf{e}$ and $\mathbf{4} \mathbf{f}$, diclofenac sodium,

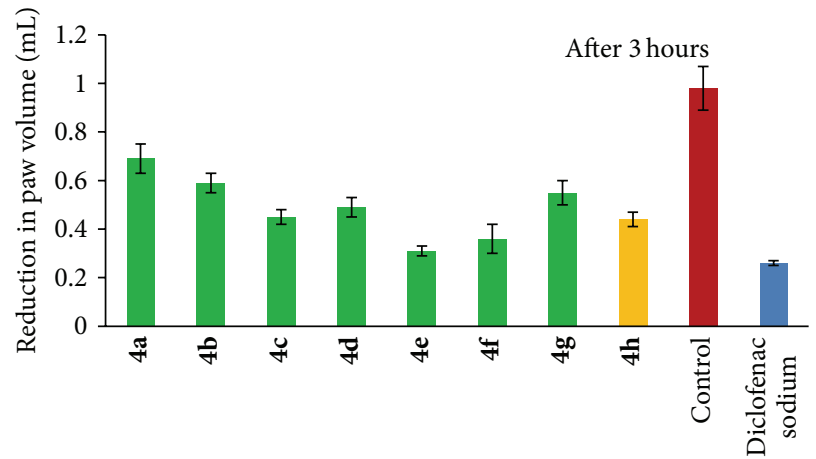

Target compounds

FIGURE 2: This histogram shows the inhibition of carrageenaninduced paw edema in rats. The histogram is plotted between target compounds $(\mathbf{4 a - h})$ at $100 \mathrm{mg} / \mathrm{kg}$, control, standard drug diclofenac sodium $(10 \mathrm{mg} / \mathrm{kg})$, on $X$ axis, and reduction in paw volume on $Y$ axis. Data has shown that the inhibition of paw edema significantly decreases by target compounds from control. Data are Mean \pm S.E.M. indicates significant decrease in inflammation form control and indicates highly significant decrease, $P<0.05$.

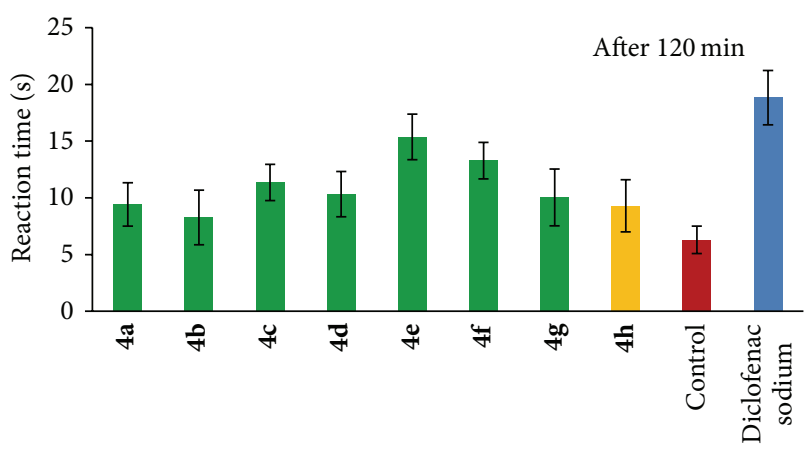

Target compounds

FIGURE 3: This histogram shows the reaction time in rats by tail immersion method. The histogram is plotted between target compounds (4a-h) at $100 \mathrm{mg} / \mathrm{kg}$, control, standard drug Diclofenac sodium $(10 \mathrm{mg} / \mathrm{kg})$, on $X$ axis, and reaction time $(\mathrm{sec})$ on $Y$ axis. Data showed that the reaction time significantly increases by target compounds from control. Data are Mean \pm S.E.M. indicates significant increase in reaction time form control and indicates highly significant increase, $P<0.05$. 

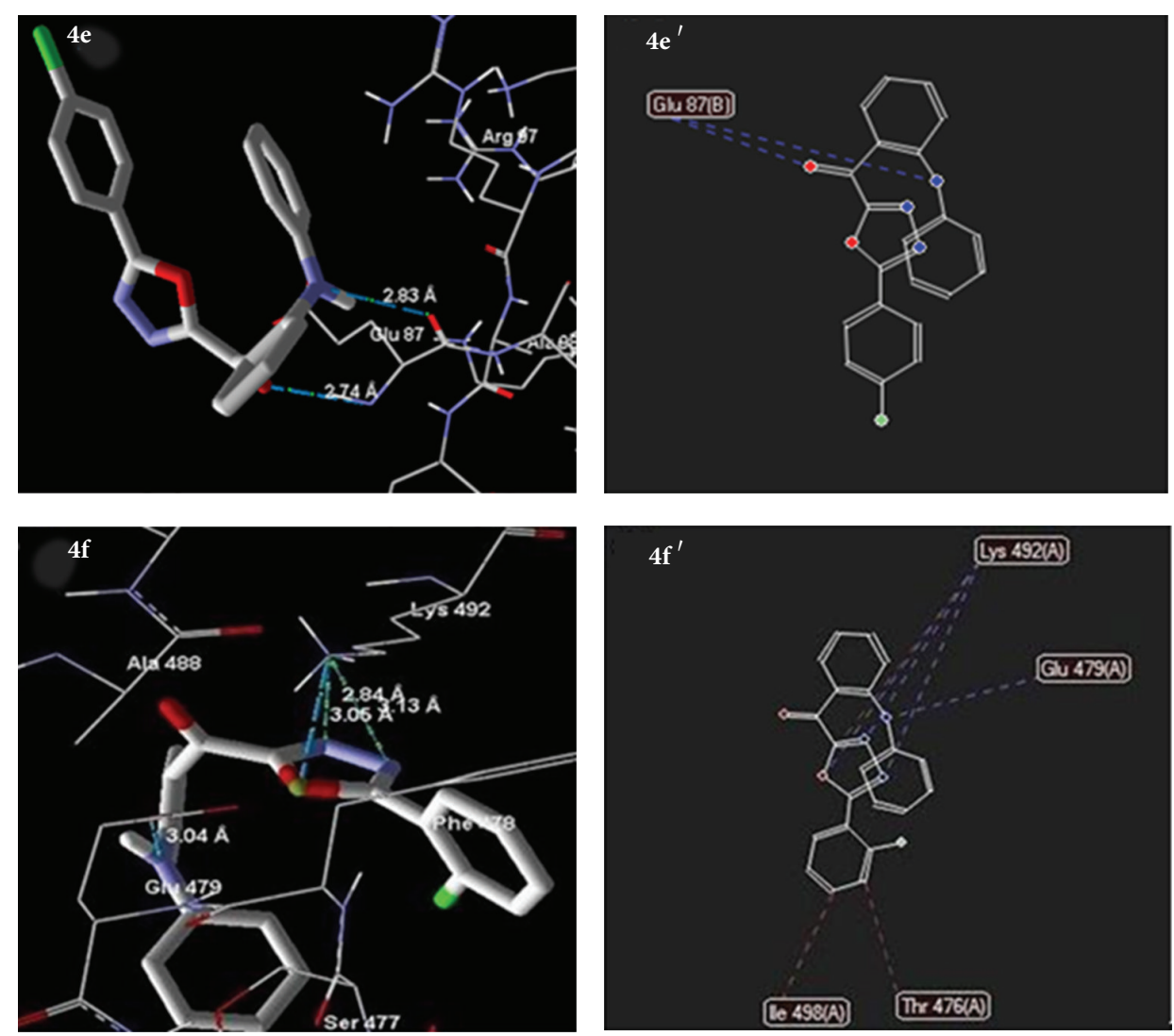

FIgURE 4: Binding modes of $\mathbf{4 e}, \mathbf{4 f}\left(\mathbf{4 e}, \mathbf{4} \mathbf{f}\right.$ as docking view and $\mathbf{4 \mathbf { e } ^ { \prime }}, \mathbf{4} \mathbf{f}^{\prime}$ as interaction view) with COX-2, where blue/green lines and red lines represent hydrogen bonding and favourable steric interactions, respectively.

TABLE 2: Analgesic activity of synthesized 1,3,4-oxadiazole analogues.

\begin{tabular}{lccc}
\hline & \multicolumn{2}{c}{ Reaction time (sec.) } & \\
Groups & $($ After 30 min $)$ & $($ After 60 min) & (After 120 min) \\
\hline Control & $5.43 \pm 1.7$ & $5.29 \pm 0.9$ & $6.30 \pm 1.2$ \\
Diclofenac sodium $(10 \mathrm{mg} / \mathrm{kg})$ & $5.07 \pm 1.6$ & $10.60 \pm 2.0$ & $18.83 \pm 2.4$ \\
$\mathbf{4 a}(100 \mathrm{mg} / \mathrm{kg})$ & $4.17 \pm 0.9$ & $6.46 \pm 0.02$ & $9.42 \pm 1.9$ \\
$\mathbf{4 b}(100 \mathrm{mg} / \mathrm{kg})$ & $5.80 \pm 1.4$ & $6.07 \pm 0.02$ & $8.27 \pm 2.4$ \\
$\mathbf{4}(100 \mathrm{mg} / \mathrm{kg})$ & $5.83 \pm 1.6$ & $8.61 \pm 0.08$ & $11.35 \pm 1.6$ \\
$\mathbf{4 d}(100 \mathrm{mg} / \mathrm{kg})$ & $4.42 \pm 0.7$ & $7.60 \pm 0.06$ & $10.32 \pm 2.0$ \\
$\mathbf{4 e}(100 \mathrm{mg} / \mathrm{kg})$ & $5.87 \pm 1.1$ & $10.34 \pm 0.09^{*}$ & $15.37 \pm 2.0^{*}$ \\
$\mathbf{4 f}(100 \mathrm{mg} / \mathrm{kg})$ & $4.72 \pm 1.0$ & $9.57 \pm 0.01^{*}$ & $13.28 \pm 1.6^{*}$ \\
$\mathbf{4 g}(100 \mathrm{mg} / \mathrm{kg})$ & $5.67 \pm 0.8$ & $7.44 \pm 0.05$ & $10.03 \pm 2.5$ \\
$\mathbf{4 h}(100 \mathrm{mg} / \mathrm{kg})$ & $4.56 \pm 1.1$ & $6.11 \pm 0.08$ & $9.30 \pm 2.3$ \\
\hline
\end{tabular}

All values are expressed as means $\pm \operatorname{SEM}(n=6),{ }^{*} P<0.05$ versus control.

and selective cyclooxygenase inhibitor-558 with receptor in terms of docking score (binding energy) was depicted in Table 3 (Figures 4 and 5).

\section{Discussion}

The common side effect associated with regular use of nonsteroidal anti-inflammatory drugs is gastric ulceration which is due to the presence of free acid functionality in the structure of the molecule. This acidic group was masked by the introduction of heterocyclic 1,3,4-oxadiazole nucleus. A series of 1,3,4-oxadiazole derivatives, which were previously synthesized in our laboratory, were subjected to antiinflammatory, analgesic, and molecular docking studies to target cyclooxygenase-2. From all the compounds, $\mathbf{4 e}$ and $\mathbf{4 f}$ having a chloro group at para and ortho positions were found to be potent in both analgesic and anti-inflammatory activity which is comparable to standard. Also the presence of para and ortho substituted halogens $(-\mathrm{Cl})$ in the compound results in enhanced biological activities. This significant increase 

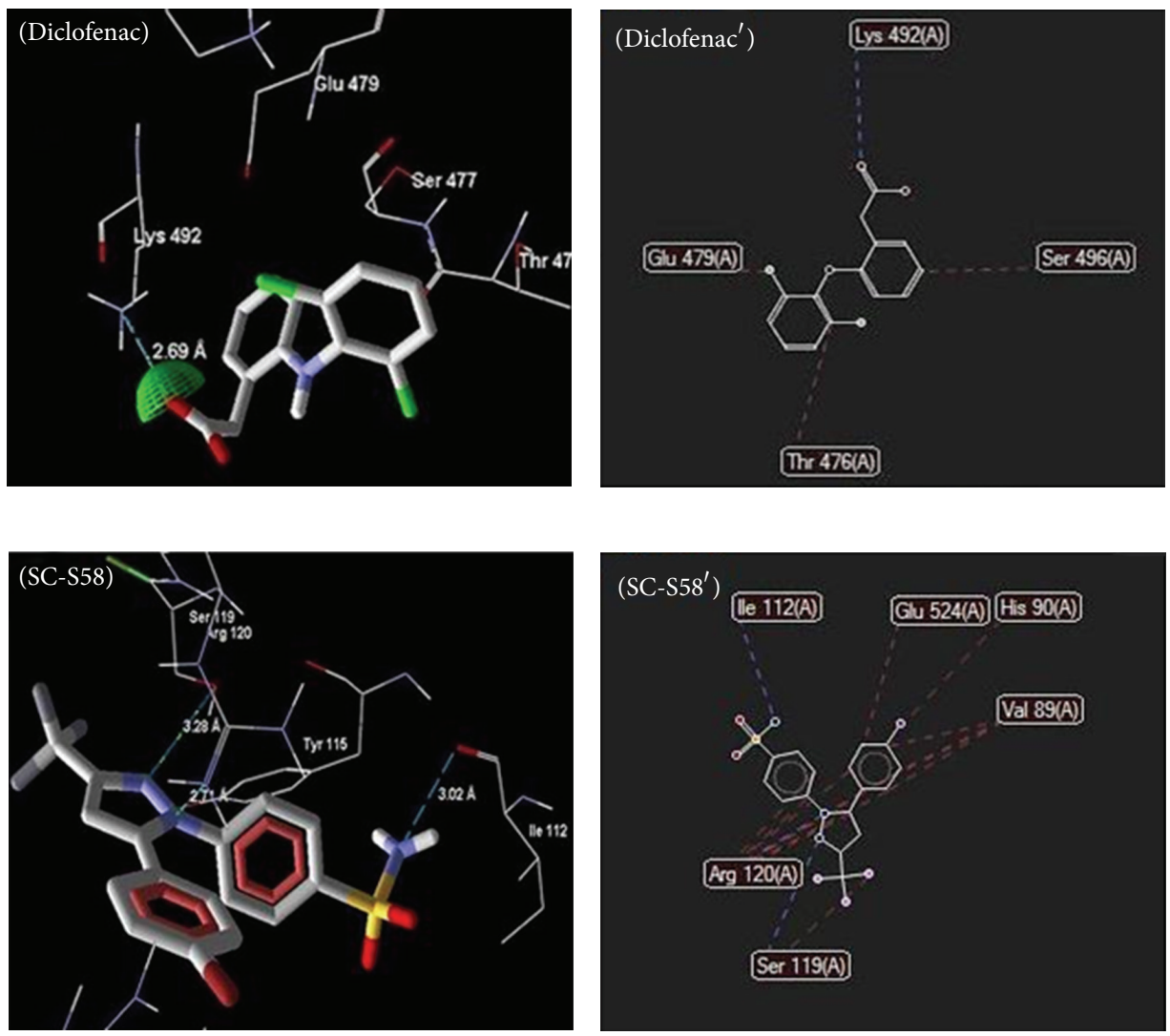

FIGURE 5: Binding modes of diclofenac, SC-S58 (diclofenac, SC-S58 as docking view and diclofenac', SC-S58' as interaction view) with COX-2, where blue/green lines and red lines represent hydrogen bonding and favourable steric interactions, respectively.

TABLE 3: Ligand-receptor interaction of target compound and standard drugs.

\begin{tabular}{|c|c|c|c|c|}
\hline Compound & Docking score & Distance & Amino acid & Group involved \\
\hline \multirow{2}{*}{$4 e$} & \multirow{2}{*}{-77.760} & 2.83 & Glu 87 & -NH- of N-phenyl anthranilic acid \\
\hline & & 2.74 & Glu 87 & Carbonyl group of N-phenyl anthranilic acidic group \\
\hline \multirow{4}{*}{$4 \mathrm{f}$} & \multirow{4}{*}{-76.499} & 3.06 & Lys 492 & -O- of oxadiazole ring \\
\hline & & 2.84 & Lys 492 & $-\mathrm{N}-$ of oxadiazole \\
\hline & & 3.13 & Lys 492 & $-\mathrm{N}-$ of oxadiazole \\
\hline & & 3.04 & Glu 479 & $-\mathrm{N}$ - of $\mathrm{N}$-phenyl group \\
\hline Diclofenac & -58.259 & 2.69 & Lys 492 & $-\mathrm{O}-$ of nitro group \\
\hline \multirow{3}{*}{ SC-S58 } & \multirow{3}{*}{-91.779} & 3.02 & Ile 112 & $-\mathrm{N}-$ of $\mathrm{SO}_{2} \mathrm{NH}_{2}$ group \\
\hline & & 2.71 & Arg 120 & $-\mathrm{N}$ - of diazole ring \\
\hline & & 3.28 & Ser 119 & $-\mathrm{N}-$ of diazole ring \\
\hline
\end{tabular}

in biological activities is attributed due to the electron withdrawing nature of halogens, which ultimately results in enhancement in lipophilicity. This enhanced lipophilicity could facilitate the penetration or passage of these compounds across the biological membrane easily.

The docking scores of $\mathbf{4 e}$ and $\mathbf{4 f}$ were much more than that of standard drug diclofenac sodium but less than that of SC-S58 (selective COX-2 inhibitor). The docking score is representative of binding energy of ligand to receptor. The amino acids that interacted with COX-2 in $4 \mathrm{e}$ are Glu 87 and Lys 492. The replacement of free carboxylic group by oxadiazole nucleus in target compounds $\mathbf{4 e}$ and $\mathbf{4 f}$ enhanced the interaction by formation of numerous hydrogen bonds with cyclooxygenase receptor. These results could be used for the development of novel, potent, and effective COX-2 inhibitors.

The carbonyl, 1,3,4-oxadiazole (act as acceptor) and $\mathrm{NH}$ - (act as donor) functionalities in the synthesized derivatives have played very important role in ligand-receptor interaction for the formation of hydrogen bonds. Results also revealed that the hydrogen bond distance is important in docking studies. Distance more than $3.2 \AA$ indicates weak hydrogen bond bonding between ligand and receptor; the distance $2.6 \AA-3.2 \AA$ represents a good hydrogen bonding. 


\section{Conclusion}

Derivatives having a 1,3,4-oxadiazole nucleus instead of a free carboxylic group are devoid of gastrointestinal side effects. The compounds $\mathbf{4 e}$ and $\mathbf{4 f}$ have shown good interaction with COX-2 enzyme and thus emerged out as potential lead for the development of novel anti-inflammatory agent with good efficacy and lesser side effects.

\section{Acknowledgment}

The authors are thankful to the M. M. College of Pharmacy, Maharishi Markandeshwar University, for providing the facility to carry out the research.

\section{References}

[1] A. Palomer, F. Cabré, J. Pascual et al., "Identification of novel cyclooxygenase-2 selective inhibitors using pharmacophore models," Journal of Medicinal Chemistry, vol. 45, no. 7, pp. 14021411, 2002.

[2] F. A. Omar, N. M. Mahfouz, and M. A. Rahman, "Design, synthesis and antiinflammatory activity of some 1,3,4-oxadiazole derivatives," European Journal of Medicinal Chemistry, vol. 31, no. 10, pp. 819-825, 1996.

[3] F. L. Lanza, "A guideline for the treatment and prevention of NSAID-induced ulcers," American Journal of Gastroenterology, vol. 93, no. 11, pp. 2037-2046, 1998.

[4] F. Buttgereit, G. R. Burmester, and L. S. Simon, "Gastrointestinal toxic side effects of nonsteroidal anti-inflammatory drugs and cyclooxygenase-2-specific inhibitors," American Journal of Medicine, vol. 110, no. 3, pp. 135-195, 2001.

[5] K. A. Metwally, S. H. Yaseen, E.-S. M. Lashine, H. M. ElFayomi, and M. E. El-Sadek, "Non-carboxylic analogues of arylpropionic acids: synthesis, anti-inflammatory activity and ulcerogenic potential," European Journal of Medicinal Chemistry, vol. 42, no. 2, pp. 152-160, 2007.

[6] A. Husain, M. S. Y. Khan, S. M. Hasan, and M. M. Alam, "2-Arylidene-4-(4-phenoxy-phenyl)but-3-en-4-olides: synthesis, reactions and biological activity," European Journal of Medicinal Chemistry, vol. 40, no. 12, pp. 1394-1404, 2005.

[7] S. Bala, S. Kamboj, V. Saini, and D. N. Prasad, "Synthesis, characterization, computational studies and evaluation of novel substituted 1, 3, 4-oxadiazoles," International Journal of Pharmacy and Pharmaceutical Sciences, vol. 4, pp. 131-135, 2012.

[8] Inderba Indian drugs, "Indian Drugs manufacturing association 102B Poonam chambers," Dr. A. B. Rd., Worli, Bombay, India. 19:301, 1982.

[9] C. A. Winter, E. A. Risley, and G. W. Nuss, "Carrageenininduced edema in hind paw of the rat as an assay for antiiflammatory drugs," Proceedings of the Society for Experimental Biology and Medicine, vol. 111, pp. 544-547, 1962.

[10] H. G. Vogel, Drug Discovery and Evaluation. Pharmacological Assay, vol. 697, Springer, New York, 2nd edition, 2002.

[11] A. Bali, R. Ohri, and P. K. Deb, "Synthesis, evaluation and docking studies on 3-alkoxy-4-methanesulfonamido acetophenone derivatives as non ulcerogenic anti-inflammatory agents," European Journal of Medicinal Chemistry, vol. 49, pp. 397-405, 2012.
[12] M. Lindner, W. Sippl, and A. A. Radwan, "Pharmacophore elucidation and molecular docking studies on 5-phenyl-1(3-pyridyl)-1H-1,2,4-triazole-3-carboxylic acid derivatives as COX-2 inhibitors," Scientia Pharmaceutica, vol. 78, no. 2, pp. 195-214, 2010. 

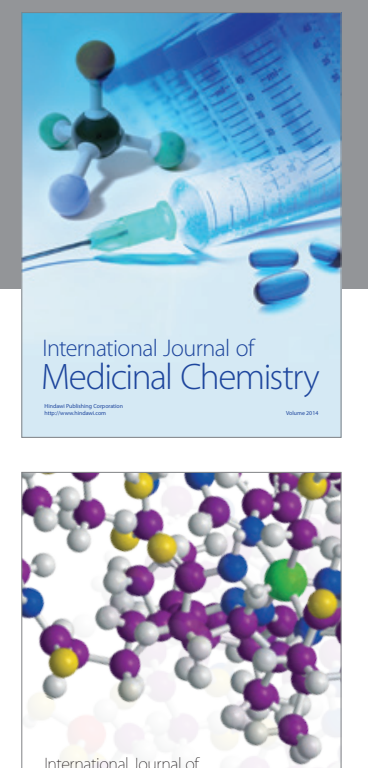

\section{Carbohydrate} Chemistry

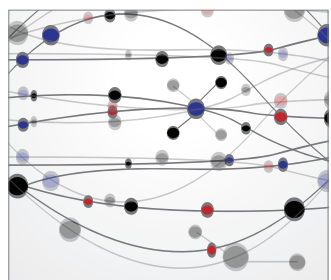

The Scientific World Journal
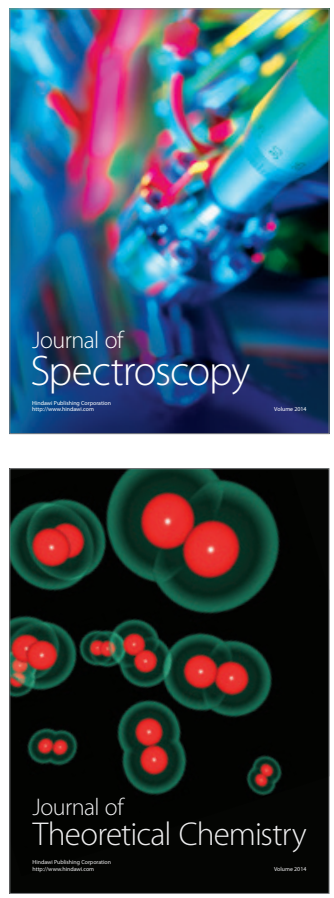
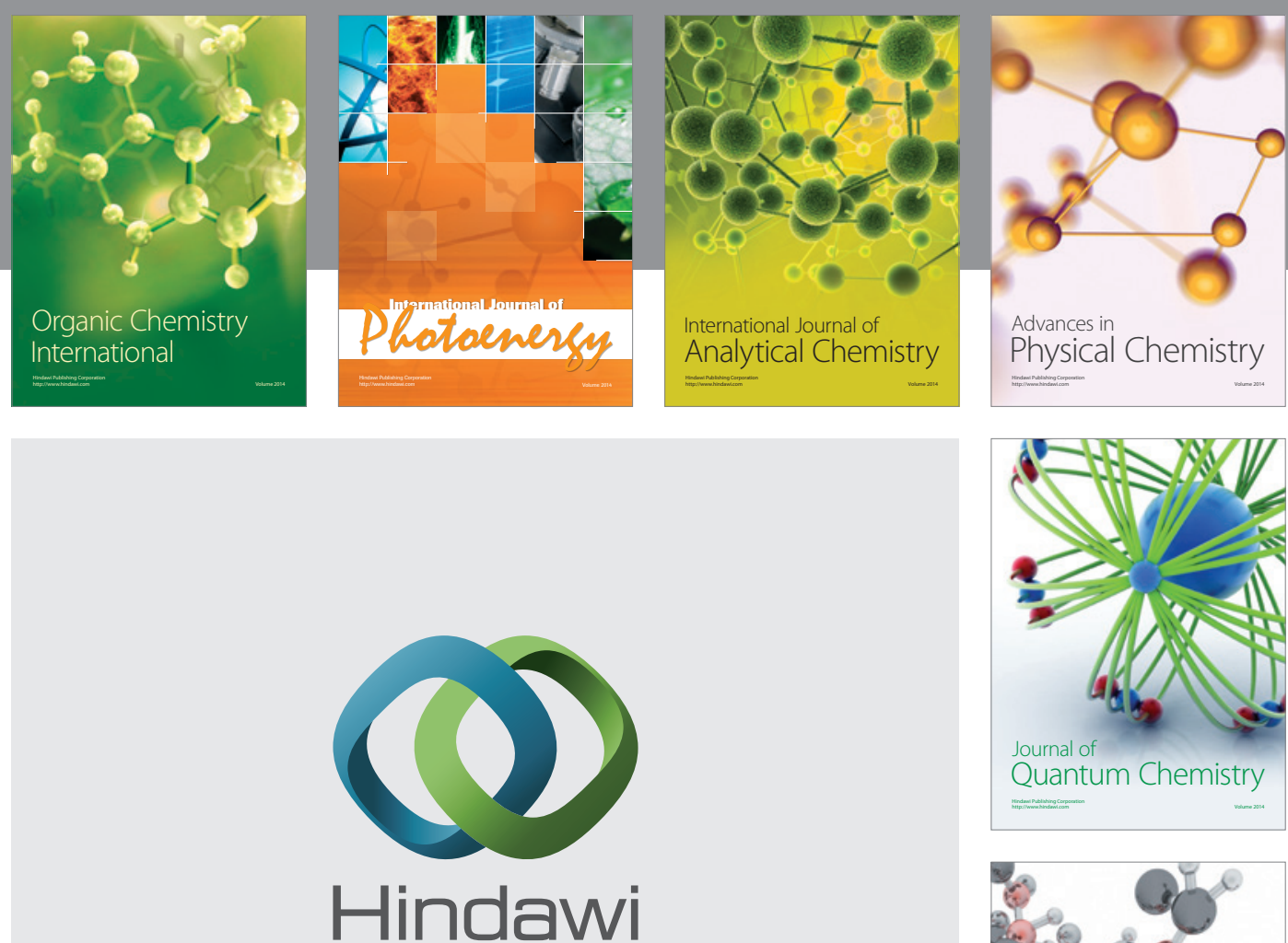

Submit your manuscripts at

http://www.hindawi.com

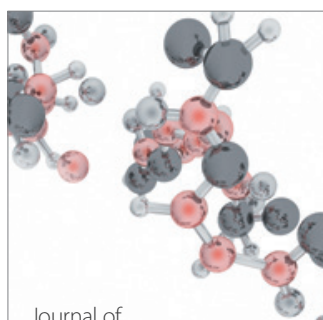

Analytical Methods

in Chemistry

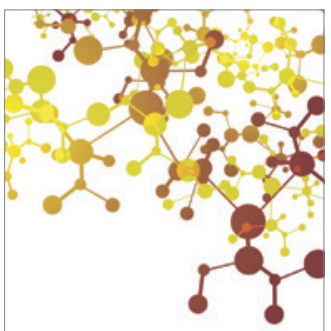

Journal of

Applied Chemistry

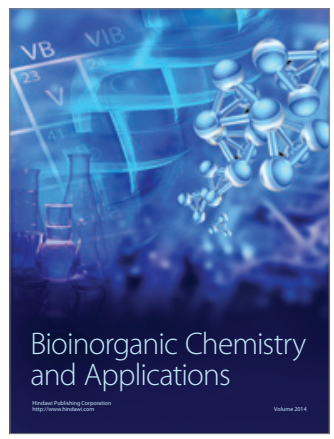

Inorganic Chemistry
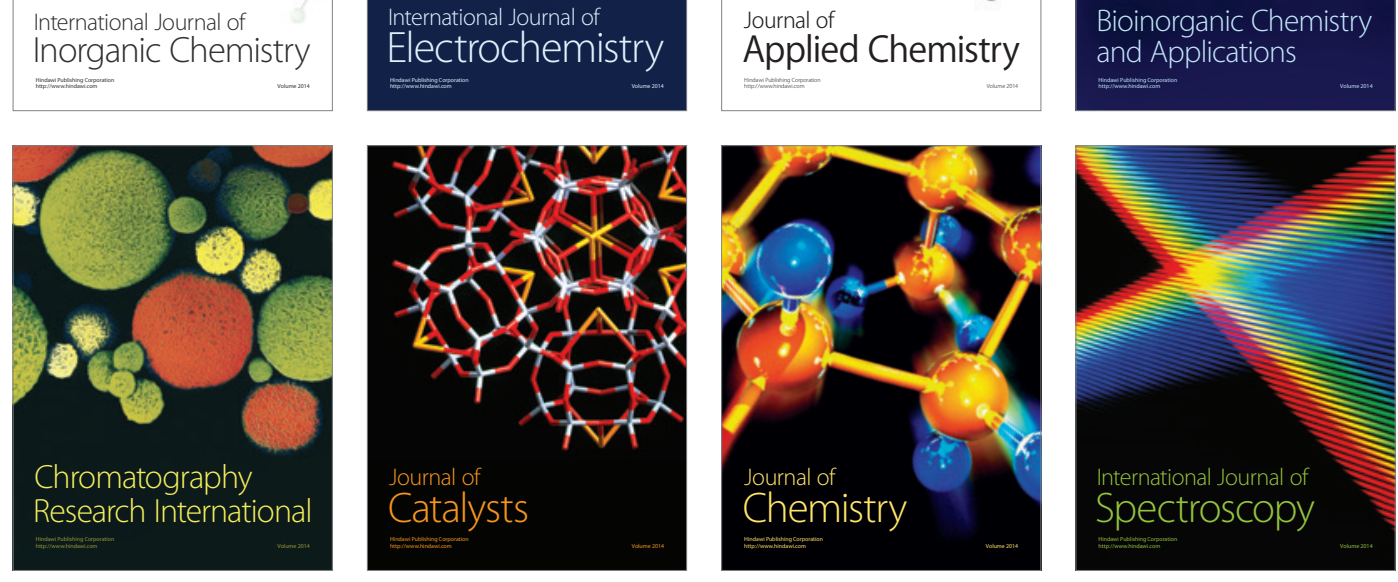